\title{
An Extension of the EDAS Method Based on the Use of Interval Grey Numbers
}

\author{
Dragisa STANUJKIC ${ }^{1}$, Edmundas Kazimieras ZAVADSKAS ${ }^{2}$, \\ Mehdi KESHAVARZ GHORABAEE ${ }^{3}$, Zenonas TURSKIS ${ }^{4}$ \\ ${ }^{1}$ Faculty of Management Zajecar, John Naisbitt University \\ Park suma Kraljevica b.b., Zajecar 19210, Serbia. \\ dragisa.stanujkic@fmz.edu.rs \\ ${ }^{2}$ Research Institute of Smart Building Technologies, Vilnius Gediminas Technical University \\ Sauletekio al. 11, Vilnius 10221, Lithuania. \\ edmundas.zavadskas@vgtu.lt \\ ${ }^{3}$ Faculty of Management and Accounting, Allameh Tabataba'i University \\ Dehkadeh-ye-Olympic, Tehran, Tehran Province, Iran. \\ m.keshavarz_gh@yahoo.com \\ ${ }^{4}$ Faculty of Civil Engineering, Vilnius Gediminas Technical University \\ Saulètekio al. 11, Vilnius 10221, Lithuania. \\ zenonas.turskis@vgtu.lt
}

Abstract. In order to solve a number of real decision-making problems, over time, a number of multiple criteria decisionmaking methods have been proposed. The EDAS method is one of the newly proposed methods; its computational procedure can be identified as innovative and also based on verified approaches. An extension of the EDAS method adapted for the use of grey numbers is considered in this paper.

Keywords: EDAS, MCDM, uncertainty, grey systems, interval grey numbers

\section{Introduction}

Multi-Criteria Decision-Making (MCDM) can be described as a process of selecting the most appropriate solution from a set of available alternatives, based on their performances in relation to a set of evaluation criteria.

The authors of a few papers published in scientific and technical journals, have proposed more MCDM methods and discussed their usage for solving various MCDM problems in a number of areas such as the economy [9], education [26], management [20, 25], production $[29,30]$, sustainable development [10], construction [40, 41], and so on. Also, in order to make these methods more efficient for solving a great number of complex real-world problems, a number of their specific extensions for the use of grey and fuzzy numbers are also proposed.

The Evaluation Based on Distance from Average Solution (EDAS) method was proposed by Keshavarz Ghorabaee et al. [16].

The computational procedure of the EDAS method can be identified as very innovative and is also based on verified approaches usedin some prominent MCDM methods, such as: SAW [14, 24], TOPSIS [13], and VIKOR [28].
Therefore, the EDAS method is expected to be able to be used to solve a number of MCDM problems very soon.

However, many real-world decision-making problems take place in environments in which the ratings of alternatives and the weights of criteria cannot be precisely determined. In such environments, classical MCDM methods, based on the use of crisp values of ratings do not provide adequate and effective decision- making.

Deng [6] proposed a grey system theory to study uncertain systems, and also introduced the concept of interval grey numbers. This theory provides an efficient approach for solving problems with significant uncertainty, and therefore has been successfully applied in many fields for the purpose of analysis, modeling and forecasting [7, 23].

On the basis of the grey system theory, many classical MCDM methods are adapted for the use of interval grey numbers, and so extended their use for solving a much larger number of problems.

As some of these extensions can be mentioned: Grey TOPSIS [3, 21, 4], COPRAS-G [38], 
SAW-G [4], WASPAS-G [40, 35, 19], the grey extension of the ARAS-G method [36], Grey AHP [1], and so on.

The above-mentioned grey extensions of MCDM methods are successfully used for solving a large number of different problems from different fields, such as selecting suppliers in the green supply chain management [22], selecting the most rational redevelopment solution of former industrial buildings with emphasis on sustainable development [29], the air traffic management [37], the supply chain performance benchmarking [18], grasp the ambiguity which exists in the utilized information and the fuzziness that appears in the human judgments and preferences [27], assessment of structural systems of high-rise buildings [33], social media platform selection [34], the robot selection [5], material selection [2], rank classification algorithms [17], personnel selection [11], evaluation of artists [12], upgrading the old monumental buildings to contemporary norms [31], and so on.

In order to enable the use of the EDAS methods for solving a much larger number of decision-making problems, i.e. problems placed in imprecise and uncertain environments, a grey extension of the EDAS method is proposed in this paper.

Therefore, the remaining part of the paper is organized as follows: In Section 2 some basic elements of the grey system theory are presented. In Section 3 the EDAS method is presented and in the subsection 3.1 an extension of the EDAS method adopted for the use of interval grey numbers is proposed. In section 4 a numerical illustration borrowed from the literature is considered in order to verify the proposed approach. Finally Section 5 presents the conclusions.

\section{The basic elements of the grey system theory}

The grey system theory is identified as an effective methodology that can be used to solve uncertain problems with partially known information.

In the grey system theory, all information can be classified into three categories that are labelled with corresponding colours - white, grey and black. There are also several types of grey numbers such as: grey numbers with only upper limits, grey numbers with only lower limits, black and white numbers and so on.
A grey number, denoted as $\otimes x$, is such a number whose exact value is unknown, but a range within which the value lies is known. A grey number with known upper, $\bar{x}$, and lower, $\underline{x}$, bounds but unknown distribution information for $x$ is called the interval grey number [21]:

$$
\otimes x=[\underline{x}, \bar{x}]=\left[x^{\prime} \in x \mid \underline{x} \leq x^{\prime} \leq \bar{x}\right]
$$

The degree of greyness is an important characteristic of grey numbers, determined as the distance between its bounds $\bar{x}-\underline{x}$.

When the degree of the greyness of an interval grey number increases, i.e., when the distance between such bounds increases and the bounds tends to infinity, $\underline{x} \rightarrow-\infty$ and $\bar{x} \rightarrow+\infty$, then the interval grey number tends to become a black number. In contrast to the previous one, when the degree of greyness decreases, then the interval grey number tends to become a white number; finally when upper and lower bounds are equal, $\underline{x}=\bar{x}$, an interval grey number becomes a white (crisp) number.

\section{The basic operations of interval grey numbers. Let $\otimes x_{1}=\left[\underline{x}_{1}, \bar{x}_{1}\right] \quad$ and} $\otimes x_{2}=\left[\underline{x}_{2}, \bar{x}_{2}\right]$ be two interval grey numbers, and $k$ is a positive real number. The basic operations of the interval grey numbers $\otimes x_{1}$ and $\otimes x_{2}$ are defined as follows [8]:

$$
\begin{aligned}
& \otimes x_{1}+\otimes x_{2}=\left[\underline{x}_{1}+\underline{x}_{2}, \bar{x}_{1}+\bar{x}_{2}\right], \\
& \otimes x_{1}-\otimes x_{2}=\left[\underline{x}_{1}-\bar{x}_{2}, \bar{x}_{1}-\underline{x}_{2}\right], \\
& \otimes x_{1} \times \otimes x_{2}=\left[\underline{x}_{1} \underline{x}_{2}, \bar{x}_{1} \bar{x}_{2}\right], \\
& \otimes x_{1} \div \otimes x_{2}=\left[\frac{\underline{x}_{1}}{\bar{x}_{2}}, \frac{\bar{x}_{1}}{\underline{x}_{2}}\right], \\
& k \otimes x_{1}=k \otimes\left[\underline{x}_{1}, \bar{x}_{1}\right]=\left[k \underline{x}_{1}, k \bar{x}_{1}\right] .
\end{aligned}
$$

The whitened value. The whitened value of an interval grey number $x_{(\lambda)}$ is a crisp number whose possible values lie between the upper and lower bounds of the interval grey number $\otimes x$. For the given interval grey number $\otimes x=[\underline{x}, \bar{x}]$ the whitened value $x_{(\lambda)}$ can be determined as follows:

$x_{(\lambda)}=(1-\lambda) \underline{x}+\lambda \bar{x}$.

where $\lambda$ denotes the whitening coefficient and $\lambda \in[0,1]$. In the particular case, when $\lambda=0.5$ Eq. (7) obtains the following form: 
$x_{(\lambda=0.5)}=\frac{1}{2}(\underline{x}+\bar{x}) \cdot$

\section{The EDAS method}

As previously mentioned, the EDAS is introduced by Keshavarz Ghorabaee et al. [16], and therefore it can be stated as a newlyproposed method. A fuzzy extension of this method was also developed by Keshavarz Ghorabaee et al. [15].

The basic ideas of the EDAS method are the use of two distance measures, namely the Positive Distance from Average (PDA) and the Negative Distance from Average (NDA); and that the evaluation of the alternatives is done according to higher values of the PDA and lower values of the NDA.

The computational procedure of the EDAS method, for a decision-making problem with $m$ criteria and $n$ alternatives, can be presented as follows (some labels used in the original EDAS method have been modified in order to make it easier the presentation of the new extension of the EDAS method proposed in the next section):

Step 1. Select the available alternatives, the most important criteria that describe the alternatives, and construct the decision-making matrix $X$, shown as follows:

$$
X=\left[\begin{array}{cccc}
x_{11} & x_{12} & \cdots & x_{1 n} \\
x_{12} & x_{22} & \cdots & x_{2 n} \\
\vdots & \vdots & \vdots & \vdots \\
x_{1 n} & x_{2 n} & \cdots & x_{m n}
\end{array}\right],
$$

where $x_{i j}$ denotes the performance rating of the alternative $i$ on the criterion $j$. We shall suppose that all $x_{i j}$ are positive numbers.

Step 2. Determine the average solution according to all criteria, shown as follows:

$x_{j}^{*}=\left(x_{1}, x_{2}, \cdots, x_{n}\right)$,

where

$x_{j}^{*}=\frac{\sum_{i=1}^{m} x_{i j}}{m}$.

Step 3. Calculate the positive distance from average $d_{i j}^{+}$and the negative distance from average $d_{i j}^{-}$, according to the type of criteria (benefit and cost), shown as follows:

$$
\begin{gathered}
d_{i j}^{+}=\left\{\begin{array}{ll}
\frac{\max \left(0,\left(x_{i j}-x_{j}^{*}\right)\right)}{x_{j}^{*}} ; & j \in \Omega_{\max } \\
\frac{\max \left(0,\left(x_{j}^{*}-x_{i j}\right)\right)}{x_{j}^{*}} ; & j \in \Omega_{\min }
\end{array},\right. \\
d_{i j}^{-}= \begin{cases}\frac{\max \left(0,\left(x_{j}^{*}-x_{i j}\right)\right)}{x_{j}^{*}} ; & j \in \Omega_{\max } \\
\frac{\max \left(0,\left(x_{i j}-x_{j}^{*}\right)\right)}{x_{j}^{*}} ; & j \in \Omega_{\min }\end{cases}
\end{gathered}
$$

where $\Omega_{\max }$ and $\Omega_{\min }$ denotes the set of the benefit criteria and the cost criteria, respectively, and $x_{j}^{*}$ is a positive real number.

Step 4. Suppose that a vector $w=\left(w_{1}, w_{2}, \ldots w_{n}\right)$ of nonnegative weights is given. Determine the weighted sum of PDA, $Q_{i}^{+}$, and the weighted sum of NDS, $Q_{i}^{-}$, for all alternatives, as follows:

$$
\begin{aligned}
& Q_{i}^{+}=\sum_{j=1}^{n} w_{j} d_{i j}^{+}, \\
& Q_{i}^{-}=\sum_{j=1}^{n} w_{j} d_{i j}^{-},
\end{aligned}
$$

where $w_{j}$ denotes nonnegative weight of the criterion $j$.

Step 5. Normalize the values of the weighted sum of the PDA and the weighted sum of the NDA for all alternatives, shown as follows:

$$
\begin{aligned}
& S_{i}^{+}=\frac{Q_{i}^{+}}{\max _{k} Q_{k}^{+}}, \\
& S_{i}^{-}=1-\frac{Q_{i}^{-}}{\max _{k} Q_{k}^{-}},
\end{aligned}
$$

where $S_{i}^{+}$and $S_{i}^{-}$denote the normalized weighted sum of the PDA and the NDA, respectively.

Step 6. Calculate the appraisal score $S_{i}$ for all alternatives, as follows:

$S_{i}=\frac{1}{2}\left(S_{i}^{+}+S_{i}^{-}\right)$.

Step 7. Rank the alternatives according to the decreasing values of appraisal score. The alternative with the highest $S_{i}$ is the best choice among the candidate alternatives. 


\subsection{The extension of the EDAS method adopted for the use of grey numbers}

An extension of the EDAS method adopted for the use of grey numbers is proposed in this section.

Let us suppose a decision-making problem in which $m$ alternatives are evaluated on the basis of $n$ criteria, where performance ratings are not exactly known and therefore they are given as the grey number $\otimes x_{i j}=\left[\underline{x}_{i j}, \bar{x}_{i j}\right]$ where $\underline{x}_{i j}$ and $\bar{x}_{i j}$ denote the minimal and the maximal expected performance ratings of the alternative $i$ with respect to the criterion $j$. Then, the computational procedure of the proposed extension of the EDAS method can be expressed concisely though the following steps:

Step 1. Construct the grey decision-making matrix as follows:

$\otimes X=\left[\begin{array}{cccc}{\left[\underline{x}_{11}, \bar{x}_{11}\right]} & {\left[\underline{x}_{12}, \bar{x}_{12}\right]} & \cdots & {\left[\underline{x}_{1 n}, \bar{x}_{1 n}\right]} \\ {\left[\underline{x}_{21}, \bar{x}_{21}\right]} & {\left[\underline{x}_{22}, \bar{x}_{22}\right]} & \cdots & {\left[\underline{x}_{2 n}, \bar{x}_{2 n}\right]} \\ \vdots & \vdots & \vdots & \vdots \\ {\left[\underline{x}_{m 1}, \bar{x}_{m 2}\right]} & {\left[\underline{x}_{m 2}, \bar{x}_{m 2}\right]} & \cdots & {\left[\underline{x}_{m n}, \bar{x}_{m n}\right]}\end{array}\right]$

whose elements $\otimes x_{i j}=\left[x_{i j}, \bar{x}_{i j}\right]$ are grey numbers.

Step 2. Determine the grey average solution according to all criteria, as follows:

$\otimes x_{j}^{*}=\left(\left[\underline{x}_{1}^{*}, \bar{x}_{1}^{*}\right],\left[\underline{x}_{2}^{*}, \bar{x}_{2}^{*}\right], \cdots\left[\underline{x}_{n}^{*}, \bar{x}_{n}^{*}\right]\right)$,

where:

$\underline{x}_{j}^{*}=\frac{\sum_{i=1}^{m} \underline{x}_{i j}}{m}$, and

$\bar{x}_{j}^{*}=\frac{\sum_{i=1}^{m} \bar{x}_{i j}}{m}$.

Step 3. Calculate the grey $\mathrm{PDA}, \otimes d_{i j}^{+}=\left[\underline{d}_{i j}^{+}, \bar{d}_{i j}^{+}\right]$, and the grey NDA, $\otimes d_{i j}^{-}=\left[\underline{d}_{i j}^{-}, \bar{d}_{i j}^{-}\right]$, according to the benefit and cost criteria.

In accordance with Eq. (3) the lower $\underline{d}_{i j}^{+}$and the upper $\bar{d}_{i j}^{+}$bounds of grey PDA can be determined as follows:

$\underline{d}_{i j}^{+}=\left\{\begin{array}{ll}\frac{\max \left(0,\left(\underline{x}_{i j}-\bar{x}_{j}^{*}\right)\right)}{0.5\left(\underline{x}_{j}^{*}+\bar{x}_{j}^{*}\right)} ; & j \in \Omega_{\max } \\ \frac{\max \left(0,\left(\underline{x}_{j}^{*}-\bar{x}_{i j}\right)\right)}{0.5\left(\underline{x}_{j}^{*}+\bar{x}_{j}^{*}\right)} ; & j \in \Omega_{\min }\end{array}\right.$,

$$
\bar{d}_{i j}^{+}=\left\{\begin{array}{ll}
\frac{\max \left(0,\left(\bar{x}_{i j}-\underline{x}_{j}^{*}\right)\right)}{0.5\left(\underline{x}_{j}^{*}+\bar{x}_{j}^{*}\right)} ; & j \in \Omega_{\max } \\
\frac{\max \left(0,\left(\bar{x}_{j}^{*}-\underline{x}_{i j}\right)\right)}{0.5\left(\underline{x}_{j}^{*}+\bar{x}_{j}^{*}\right)} ; & j \in \Omega_{\min }
\end{array} .\right.
$$

Similarly, the lower $\underline{d}_{i j}^{-}$and the upper $\bar{d}_{i j}^{-}$ bounds of the grey NDA can be determined, as follows:

$$
\begin{gathered}
\underline{d}_{i j}^{-}=\left\{\begin{array}{ll}
\frac{\max \left(0,\left(\underline{x}_{j}^{*}-\bar{x}_{i j}\right)\right)}{0.5\left(\underline{x}_{j}^{*}+\bar{x}_{j}^{*}\right)} ; & j \in \Omega_{\max } \\
\frac{\max \left(0,\left(\underline{x}_{i j}-\underline{x}_{j}^{*}\right)\right)}{0.5\left(\underline{x}_{j}^{*}+\bar{x}_{j}^{*}\right)} ; & j \in \Omega_{\min }
\end{array},\right. \\
\bar{d}_{i j}^{-}=\left\{\begin{array}{ll}
\frac{\max \left(0,\left(\bar{x}_{j}^{*}-\underline{x}_{i j}\right)\right)}{0.5\left(\underline{x}_{j}^{*}+\bar{x}_{j}^{*}\right)} ; & j \in \Omega_{\max } \\
\frac{\max \left(0,\left(\bar{x}_{i j}-\underline{x}_{j}^{*}\right)\right)}{0.5\left(\underline{x}_{j}^{*}+\bar{x}_{j}^{*}\right)} ; & j \in \Omega_{\min }
\end{array} .\right.
\end{gathered}
$$

Step 4. Determine the weighted sum of the grey PDA, $\otimes Q_{i}^{+}=\left[\underline{Q}_{i}^{+}, \bar{Q}_{i}^{+}\right]$, and the weighted sum of the grey NDA, $\otimes Q_{i}^{-}=\left[\underline{Q}_{i}^{-}, \bar{Q}_{i}^{-}\right]$, for all alternatives, shown as follows:

$$
\begin{aligned}
& \underline{Q}_{i}^{+}=\sum_{j=1}^{n} w_{j} \underline{d}_{i j}^{+}, \\
& \bar{Q}_{i}^{+}=\sum_{j=1}^{n} w_{j} \bar{d}_{i j}^{+}, \\
& \underline{Q}_{i}^{-}=\sum_{j=1}^{n} w_{j} \underline{d}_{i j}^{-}, \text {and } \\
& \bar{Q}_{i}^{-}=\sum_{j=1}^{n} w_{j} \bar{d}_{i j}^{-} .
\end{aligned}
$$

Step 5. Normalize the values of the weighted sum of the grey PDA and the weighted sum of the grey NDA for all alternatives, shown as follows:

$$
\begin{aligned}
& \underline{S}_{i}^{+}=\frac{\underline{Q}_{i}^{+}}{\max _{k} \bar{Q}_{k}^{+}}, \\
& \bar{S}_{i}^{+}=\frac{\bar{Q}_{i}^{+}}{\max _{k} \bar{Q}_{k}^{+}}, \\
& \underline{S}_{i}^{-}=1-\frac{\bar{Q}_{i}^{-}}{\max _{k} \bar{Q}_{k}^{+}}, \text {and } \\
& \bar{S}_{i}^{-}=1-\frac{\underline{Q}_{i}^{-}}{\max _{k} \bar{Q}_{k}^{+}},
\end{aligned}
$$

where $\underline{S}_{i}^{+}$and $\bar{S}_{i}^{+}$denote the lower and the upper bounds of the normalized weighted sum 
of the grey PDA, $\otimes S_{i}^{+}=\left[\underline{S}_{i}^{+}, \bar{S}_{i}^{+}\right]$, and $\underline{S}_{i}^{-}$and $\bar{S}_{i}^{-}$denote the lower and the upper bounds of the normalized weighted sum of the grey NDA, $\otimes S_{i}^{-}=\left[\underline{S}_{i}^{-}, \bar{S}_{i}^{-}\right]$, respectively.

Step 6. Calculate the appraisal score $S_{i}$ for all alternatives, as follows:

$$
\begin{aligned}
& S_{i}=\frac{1}{4}\left(\underline{S}_{i}^{+}+\bar{S}_{i}^{+}+\underline{S}_{i}^{-}+\bar{S}_{i}^{-}\right), \text {or } \\
& S_{i}=\frac{1}{2}\left[(1-\alpha)\left(\underline{S}_{i}^{-}+\underline{S}_{i}^{+}\right)+\alpha\left(\bar{S}_{i}^{-}+\bar{S}_{i}^{+}\right)\right],
\end{aligned}
$$

when decision-makers want to give different importance to lower or upper bounds of the grey interval or want to perform some analysis.

Step 7. Rank the alternatives according to the decreasing values of appraisal score.
The alternative with the highest $S_{i}$ is the best choice among the candidate alternatives.

\section{A numerical illustration}

In this section a numerical illustration is considered in order to explain the proposed approach. The numerical illustration of a selection of contractors for a construction project, adopted from [38], is applied to illustrate the feasibility of the proposed extension. The selected criteria, the criteria weights and the optimization directions are shown in Table 1.

The grey average solution obtained by using Eqs. (21) and (22) are shown in Table 2.

The positive and negative grey distances from the average are shown in Table 3 and Table 4.

\begin{tabular}{|c|c|c|c|c|c|c|c|c|}
\hline & \multicolumn{8}{|c|}{ Criteria } \\
\hline & \multicolumn{2}{|c|}{ Technical } & \multicolumn{2}{|c|}{ Financial } & \multicolumn{2}{|c|}{$\begin{array}{l}\text { Integrated contractual and } \\
\text { administrative }\end{array}$} & \multicolumn{2}{|c|}{ Time of the project } \\
\hline & \multicolumn{2}{|c|}{ (score) } & \multicolumn{2}{|c|}{ (thousand $€$ ) } & \multicolumn{2}{|c|}{ (score) } & \multicolumn{2}{|c|}{ (days) } \\
\hline Optimization & \multicolumn{2}{|c|}{$\max$} & \multicolumn{2}{|c|}{$\max$} & \multicolumn{2}{|c|}{$\max$} & \multicolumn{2}{|c|}{$\min$} \\
\hline$w_{i}$ & \multicolumn{2}{|c|}{0.15} & \multicolumn{2}{|c|}{0.4} & \multicolumn{2}{|c|}{0.2} & \multicolumn{2}{|c|}{0.25} \\
\hline & \multicolumn{2}{|c|}{$C_{1}$} & \multicolumn{2}{|c|}{$C_{2}$} & \multicolumn{2}{|c|}{$C_{3}$} & \multicolumn{2}{|c|}{$C_{4}$} \\
\hline Contractors & $l_{1}$ & $u_{1}$ & $l_{2}$ & $u_{2}$ & $l_{3}$ & $u_{3}$ & $l_{4}$ & $u_{4}$ \\
\hline$A_{1}$ & 64 & 85 & 50 & 55 & 60 & 80 & 75 & 80 \\
\hline$A_{2}$ & 57 & 81 & 52 & 56 & 62 & 76 & 70 & 75 \\
\hline$A_{3}$ & 61 & 78 & 55 & 58 & 53 & 61 & 70 & 75 \\
\hline$A_{4}$ & 59 & 93 & 54 & 62 & 55 & 72 & 80 & 90 \\
\hline$A_{5}$ & 63 & 89 & 61 & 68 & 54 & 63 & 65 & 78 \\
\hline
\end{tabular}

Table 1. The initial decision-making matrix

Table 2. The grey average solution

\begin{tabular}{|c|ccccccccc|}
\hline & \multicolumn{2}{|c}{$C_{1}$} & \multicolumn{2}{c}{$C_{2}$} & \multicolumn{2}{c}{$C_{3}$} & \multicolumn{2}{c|}{$C_{4}$} \\
\hline & $l_{1}$ & $u_{1}$ & $l_{2}$ & $u_{2}$ & $l_{3}$ & $u_{3}$ & $l_{4}$ & $u_{4}$ \\
\hline$\otimes x_{j}^{*}$ & 60.80 & 85.20 & 54.40 & 59.80 & 56.80 & 70.40 & 72.00 & 79.60 \\
\hline
\end{tabular}

Table 3. The positive grey distance from the average

\begin{tabular}{|c|cccccccc|}
\hline Criteria & \multicolumn{2}{|c}{$C_{1}$} & \multicolumn{2}{c}{$C_{2}$} & \multicolumn{2}{c|}{$C_{3}$} & \multicolumn{2}{c|}{$C_{4}$} \\
\hline Alternatives & $l_{1}$ & $u_{1}$ & $l_{2}$ & $u_{2}$ & $l_{3}$ & $u_{3}$ & $l_{4}$ & $u_{4}$ \\
\hline$A_{1}$ & 0.000 & 0.332 & 0.000 & 0.011 & 0.000 & 0.365 & 0.000 & 0.061 \\
$A_{2}$ & 0.000 & 0.277 & 0.000 & 0.028 & 0.000 & 0.302 & 0.000 & 0.127 \\
$A_{3}$ & 0.000 & 0.236 & 0.000 & 0.063 & 0.000 & 0.066 & 0.000 & 0.127 \\
$A_{4}$ & 0.000 & 0.441 & 0.000 & 0.133 & 0.000 & 0.239 & 0.000 & 0.000 \\
$A_{5}$ & 0.000 & 0.386 & 0.021 & 0.238 & 0.000 & 0.097 & 0.000 & 0.193 \\
\hline
\end{tabular}

Table 4. The negative grey distance from the average

\begin{tabular}{|c|cccccccc|}
\hline Criteria & \multicolumn{2}{|c}{$C_{1}$} & \multicolumn{2}{c}{$C_{2}$} & \multicolumn{2}{c}{$C_{3}$} & \multicolumn{2}{c|}{$C_{4}$} \\
\hline Alternatives & $l_{1}$ & $u_{1}$ & $l_{2}$ & $u_{2}$ & $l_{3}$ & $u_{3}$ & $l_{4}$ & $u_{4}$ \\
\hline$A_{1}$ & 0.000 & 0.290 & 0.000 & 0.172 & 0.000 & 0.164 & 0.000 & 0.106 \\
$A_{2}$ & 0.000 & 0.386 & 0.000 & 0.137 & 0.000 & 0.132 & 0.000 & 0.040 \\
$A_{3}$ & 0.000 & 0.332 & 0.000 & 0.084 & 0.000 & 0.274 & 0.000 & 0.040 \\
$A_{4}$ & 0.000 & 0.359 & 0.000 & 0.102 & 0.000 & 0.242 & 0.005 & 0.237 \\
$A_{5}$ & 0.000 & 0.304 & 0.000 & 0.000 & 0.000 & 0.258 & 0.000 & 0.079 \\
\hline
\end{tabular}


The weighted and normalized weighted grey sums of positive and negative distances from the average, obtained by using Eqs. (27) to (34), are shown in Table 5.

Table 5. The weighted and the normalized weighted grey sums of positive and negatives distances from the average

\begin{tabular}{|c|ccccccccc|}
\hline & \multicolumn{2}{|c}{$\otimes Q_{i}^{+}$} & \multicolumn{2}{c}{$\otimes Q_{i}^{-}$} & \multicolumn{2}{c}{$\otimes S_{i}^{+}$} & \multicolumn{2}{c|}{$\otimes S_{i}^{-}$} \\
\hline \multirow{2}{*}{ Alternatives } & $Q_{i}^{+}$ & $\bar{Q}_{i}^{+}$ & $\underline{Q}_{i}^{-}$ & $\bar{Q}_{i}^{-}$ & $\underline{S}_{i}^{+}$ & $\bar{S}_{i}^{+}$ & $\underline{S}_{i}^{-}$ & $\bar{S}_{i}^{-}$ \\
\hline$A_{1}$ & 0.000 & 0.142 & 0.000 & 0.171 & 0.000 & 0.643 & 0.153 & 1.000 \\
$A_{2}$ & 0.000 & 0.145 & 0.000 & 0.149 & 0.000 & 0.655 & 0.264 & 1.000 \\
$A_{3}$ & 0.000 & 0.105 & 0.000 & 0.148 & 0.000 & 0.477 & 0.268 & 1.000 \\
$A_{4}$ & 0.000 & 0.167 & 0.001 & 0.202 & 0.000 & 0.757 & 0.000 & 0.993 \\
$A_{5}$ & 0.008 & 0.221 & 0.000 & 0.117 & 0.038 & 1.000 & 0.422 & 1.000 \\
\hline
\end{tabular}

Finally, the appraisal score $S_{i}$, calculated by using Eq. (35), is presented in Table 6 .

Table 6. The appraisal score and the ranking order of the considered alternatives

\begin{tabular}{|c|c|c|}
\hline Alternatives & $S_{i}$ & Rank \\
\hline$A_{1}$ & 0.449 & 3 \\
$A_{2}$ & 0.480 & 2 \\
$A_{3}$ & 0.436 & 5 \\
$A_{4}$ & 0.438 & 4 \\
$A_{5}$ & 0.615 & 1 \\
& & \\
\hline
\end{tabular}

As it is shown in Table 7, the ranking orders of the considered alternative obtained by the

proposed extension of the EDAS method is similar to the ranking orders obtained in [38] and [32], which confirms the proposed extension of the EDAS method.

Table 7. The ranking results obtained using the COPRAS and MOORA methods

\begin{tabular}{|c|c|c|c|}
\hline Alterntives & $\begin{array}{c}{[38]} \\
\text { Rank }\end{array}$ & $\begin{array}{c}{[32]} \\
\text { Rank }\end{array}$ & $\begin{array}{c}\text { EDAS - G } \\
\text { Rank }\end{array}$ \\
\hline$A_{1}$ & $3=4$ & 3 & 3 \\
$A_{2}$ & 2 & 2 & 2 \\
$A_{3}$ & 5 & 5 & 5 \\
$A_{4}$ & $3=4$ & 4 & 4 \\
$A_{5}$ & 1 & 1 & 1 \\
\hline
\end{tabular}

\section{Conclusion}

This paper presents an extension of the EDAS method based on the use of interval grey numbers.

On the basis of the proposed extension, the EDAS method can be used most efficiently for solving a larger number of complex real-world decision-making problems, especially those associated with an uncertainty, and so it can be applied in many fields for the purpose of analysis, modeling and forecasting.

Finally, the usability and effectiveness of the proposed approach are checked on a known MCDM example. The obtained results confirm the usability of the proposed approach.

\section{REFERENCES}

1. Baradaran, V., Azarnia, S. (2013). An Approach to Test Consistency and Generate Weights from Grey Pairwise Matrices in Grey Analytical Hierarchy Process. Journal of Grey System, 25(2), pp. 46-68.

2. Chatterjee, P., Chakraborty, S. (2012). Material selection using preferential ranking methods. Materials \& Design, 35, pp. 384-393.

3. Chen, M. F., Tzeng, G. H. (2004). Combining grey relation and TOPSIS concepts for selecting an expatriate host country. Mathematical and Computer Modelling, 40(13), pp. 1473-1490. 
4. Chen, T. Y. (2012). Comparative analysis of SAW and TOPSIS based on intervalvalued fuzzy sets: Discussions on score functions and weight constraints. Expert Systems with Applications, 39(2), pp. 1848-1861.

5. Datta, S., Sahu, N., Mahapatra, S. (2013). Robot selection based on greyMULTIMOORA approach. Grey Systems: Theory and Application, 3(2), pp.201-232.

6. Deng, J. L. (1982). Control problems of grey systems. Systems \& Control Letters, 1(5), pp. 288-294.

7. Deng, J. L. (1989). Introduction to grey system theory. The Journal of grey system, l(1), pp.1-24.

8. Deng, J. L. (1992). An Introduction to Grey Mathematics-Grey Hazy Set. Press of Huazhong University of Science and Technology, Wuhan.

9. Ghadikolaei, A. S., Esbouei, S. K., Antucheviciene, J. (2014). Applying fuzzy MCDM for financial performance evaluation of Iranian companies. Technological and Economic Development of Economy, 20(2), pp. 274-291.

10. Ghosh, S., Chakraborty, T., Saha, S., Majumder, M., Pal, M. (2016). Development of the location suitability index for wave energy production by ANN and MCDM techniques. Renewable and Sustainable Energy Reviews, 59, pp.1017-1028.

11. Hashemkhani Zolfani, S., \& Antucheviciene, J. (2012). Team member selecting based on AHP and TOPSIS grey. Inzinerine Ekonomika-Engineering Economics, 23(4), pp.424-434.

12. Hashemkhani Zolfani, S., Rezaeiniya, N., Saparauskas, J. (2012). Selecting the best multi-role artist of rock bands of Iran 2000s by applying ANP and TOPSIS grey. Economic Computation and Economic Cybernetics Studies and Research, 46(2), pp.193-211.

13. Hwang, C. L., Yoon, K. (1981). Multiple attribute decision making: methods and applications. Springer, New York.

14.Kaliszewski, I., Podkopaev, D. (2016). Simple additive weighting - A metamodel for multiple criteria decision analysis methods. Expert Systems with Applications, 54(15), pp. 155-161.
15. Keshavarz Ghorabaee, M., Zavadskas, E. K., Amiri, M., urskis, Z. (2016). Extended EDAS method for fuzzy multi-criteria decision-making: an application to supplier selection. International Journal of Computers Communications \& Control, 11(3), pp.358-371.

16. Keshavarz Ghorabaee, M., Zavadskas, E. K., Olfat, L., Turskis, Z. (2015). Multicriteria inventory classification using a new method of evaluation based on distance from average solution (EDAS). Informatica, 26(3), pp. 435-451.

17. Kou, G., Lu, Y., Peng, Y., Shi, Y. (2012). Evaluation of classification algorithms using MCDM and rank correlation. International Journal of Information Technology \& Decision Making, 11(01), pp. 197-225.

18. Kumar Sahu, A., Datta, S., \& Sankar Mahapatra, S. (2014). Supply chain performance benchmarking using greyMOORA approach: An empirical research. Grey Systems: Theory and Application, 4(1), pp. 24-55.

19. Leonaviciute, G., Dejus, T., \& Antucheviciene, J. (2016). Analysis and prevention of construction site accidents. Gradevinar, 68(05), 399-410.

20. Li, M., Jin, L., \& Wang, J. (2014). A new MCDM method combining QFD with TOPSIS for knowledge management system selection from the user's perspective in intuitionistic fuzzy environment. Applied soft computing, 21, pp. 28-37.

21. Lin, Y. H., Lee, P. C., Chang, T. P., \& Ting, H. I. (2008). Multi-attribute group decision making model under the condition of uncertain information. Automation in Construction, 17(6), pp. 792-797.

22. Liou, J. J., Tamosaitiene, J., Zavadskas, E. K., Tzeng, G. H. (2016). New hybrid COPRAS-G MADM Model for improving and selecting suppliers in green supply chain management. International Journal of Production Research, 54(1), pp. 114-134.

23. Liu, S. F., Lin, Y. (2006). Grey information: theory and practical applications. Springer Science \& Business Media. 
24. MacCrimmon, K. R. (1968). Decisionmaking among multiple-attribute alternatives: a survey and consolidated approach (No. RM-4823-ARPA), RAND memorandum.

25. Mardani, A., Jusoh, A., Zavadskas, E. K., Zakuan, N., Valipour, A., \& Kazemilari, M. (2016). Proposing a new hierarchical framework for the evaluation of quality management practices: a new combined fuzzy hybrid MCDM approach. Journal of Business Economics and Management, 17(1), pp. 1-16.

26. Marzouk, M., \& Awad, E. (2016). Establishing Multi-level Performance Condition Indices for Public Schools Maintenance Program Using AHP and Fuzzy Logic. Studies in Informatics and Control, 25(3), pp. 343-352.

27. Mehrjerdi, Y. Z. (2014). Strategic system selection with linguistic preferences and grey information using MCDM. Applied Soft Computing, 18, pp. 323-337.

28. Opricovic, S. (1998). Visekriterijumska optimizacija u građevinarstvu [Multicriteria optimization of civil engineering systems], Faculty of Civil Engineering, Belgrade.

29. Pavlovskis, M., Antucheviciene, J., \& Migilinskas, D. (2016). Application of MCDM and BIM for Evaluation of Asset Redevelopment Solutions. Studies in Informatics and Control, 25(3), pp.293-302.

30. Ren, J., Manzardo, A., Mazzi, A., Zuliani, F., \& Scipioni, A. (2015). Prioritization of bioethanol production pathways in China based on life cycle sustainability assessment and multicriteria decisionmaking. The International Journal of Life Cycle Assessment, 20(6), pp. 842-853.

31. Siozinyte, E., Antucheviciene, J., \& Kutut, V. (2014). Upgrading the old vernacular building to contemporary norms: multiple criteria approach. Journal of Civil Engineering and Management, 20(2), pp. 291-298.

32. Stanujkic, D., Magdalinovic, N., Stojanovic, S., \& Jovanovic, R. (2012). Extension of ratio system part of MOORA method for solving decision-making problems with interval data. Informatica, 23(1), pp. 141-154.
33. Tamosaitiene, J., \& Gaudutis, E. (2013). Complex assessment of structural systems used for high-rise buildings. Journal of Civil Engineering and Management, 19(2), pp. 305-317.

34. Tavana, M., Momeni, E., Rezaeiniya, N., Mirhedayatian, S. M., \& Rezaeiniya, H. (2013). A novel hybrid social media platform selection model using fuzzy ANP and COPRAS-G. Expert Systems with Applications, 40(14), pp. 5694-5702.

35. Turskis, Z., Daniunas, A., Zavadskas, E. K., \& Medzvieckas, J. (2016). Multicriteria evaluation of building foundation alternatives. Computer-Aided Civil and Infrastructure Engineering, 31(9), pp. 717-729.

36.Turskis, Z., Zavadskas, E. K. (2010). A novel method for multiple criteria analysis: grey additive ratio assessment (ARAS-G) method. Informatica, 21(4), pp. 597-610.

37. Yan, J., Xie, Z., Chen, K., Lin, Y. (2015). Air traffic management system safety evaluation based on grey evidence theory. The Journal of Grey System, 27(3), pp. 2339.

38. Zavadskas, E. K., Kaklauskas, A., Turskis, Z., Tamosaitiene, J. (2009). Multi-attribute decision-making model by applying grey numbers. Informatica, 20(2), pp. 305-320.

39. Zavadskas, E. K., Kaklauskas, A., Turskis, Z., \& Tamosaitiene, J. (2008). Selection of the effective dwelling house walls by applying attributes values determined at intervals. Journal of Civil Engineering and Management, 14(2), pp. 85-93.

40. Zavadskas, E. K., Turskis, Z., Antucheviciene, J. (2015). Selecting a Contractor by Using a Novel Method for Multiple Attribute Analysis: Weighted Aggregated Sum Product Assessment with Grey Values (WASPAS-G). Studies in Informatics and Control, 24(2), 141-150.

41. Zavadskas, E. K., Turskis, Z., Volvaciovas, R., Kildiene, S. (2013). Multi-criteria assessment model of technologies. Studies in Informatics and Control, 22(4), pp. 249-258. 